\title{
Metallurgical Characterization of the Interfaces in Steel Plates Clad with Austenitic Steel or High Ni Alloys by Hot Rolling
}

\author{
Fabio Giudice ${ }^{1, *(\mathbb{D}}$, Severino Missori ${ }^{2}$, Francesco Murdolo ${ }^{3}$ and Andrea Sili ${ }^{3, *(1)}$ \\ 1 Dipartimento di Ingegneria Civile e Architettura, Università di Catania, 95123 Catania, Italy \\ 2 Dipartimento di Ingegneria Industriale, Università di Roma-Tor Vergata, 00133 Roma, Italy; \\ missori@uniroma2.it \\ 3 Dipartimento di Ingegneria, Università di Messina, 98166 Messina, Italy; franzmur@libero.it \\ * Correspondence: fgiudice@dii.unict.it (F.G.), asili@unime.it (A.S.); Tel.: +39-095-7382416 (F.G.)
}

Received: 30 January 2020; Accepted: 18 February 2020; Published: 21 February 2020

\begin{abstract}
An integrated experimental-theoretical approach to the metallurgical characterization of the interfaces in steel plates clad by hot rolling is proposed. Three different couplings of materials have been studied: ASTM A 515 Gr.60 low carbon steel clad with austenitic stainless steel AISI 304L; extra low carbon steel ASTM A283 clad with high Ni content Alloy 59; and, low carbon steel AISI 1010 clad with Cu-Ni Monel 400. Experimental investigations, which are addressed to analyse the microstructural changes near the interfaces and identify the present phases, have been carried out through scanning electron microscopy (SEM) observations, microanalytical measurements by energy dispersive spectroscopy (EDS), and Vickers microhardness tests. In all of the cases examined, the zones that are affected by detrimental microstructural changes results in being considerably less thick than the overall cladding layer. Simulations that are based on theoretical diffusion modelling have been integrated to the experimental characterization by introducing a cladding parameter that acts on the diffusion bonding efficiency, in order to evaluate the effects of process temperature and time variations on diffusion bonding efficiency and stability. In particular, this analytical investigation has shown how the shorter is the duration of the diffusion transient and the higher the temperature, the lower results the sensitivity of the diffusion processes to temperature fluctuations.
\end{abstract}

Keywords: cladding; hot rolling; diffusion; carbon steel; austenitic stainless steel; nickel and nickel-copper alloys

\section{Introduction}

Low carbon steel plates or tubes, clad with different types of alloys, represent an economic solution to the growing demand for quality materials. They benefit from having the peculiar properties of both base and clad metal, achieving good results in terms of mechanical performance, corrosion resistance, and lower cost if compared to the use of a massive high alloyed metal. For this reason, clad steels have been utilized with great success for several decades in process vessels, heat exchangers, chemical tanks, besides a variety of storage facilities [1], also representing a great potential for applications in structural engineering [2] and shipbuilding [3].

Clad metals can be selected from a wide variety; in particular, austenitic steel, high $\mathrm{Ni}$, or $\mathrm{Ni}-\mathrm{Cu}$ alloys provide specific properties in a corrosive environment, expanding the fields of use of the base material [4].

The industrial production of steels with cladding thickness of the order of millimeter can be performed through several methods, such as roll bonding, explosion welding, and weld overlay 
cladding [5]. Uniform bonding interface and high shear strength between carbon steel and stainless steel can be obtained by overlay welding; however, the generated high energy and consequent thermal stress lead to interface deterioration [6]. By means of solid state processes, it is possible to obtain, without melting, the continuity between substrate and coating, avoiding the negative effects of dilution that might occur in the case of metals deposition by fusion welding $[7,8]$. The bonding interface that was obtained by explosion welding is wavy [9], so that shear strength of the interface is high, but this process needs specific requirements, as a dedicate place for explosion, and it results in serious pollution.

Although each method has its own advantages, the hot rolling technique is the most common process due to its high efficiency and low cost [10]; moreover, it allows for obtaining products in the form of plates, bars, or reinforced tubes [11-13]. In addition, it can bond couples of metals with different mechanical properties [6]. When compared with explosion welding, hot rolling produces clad steels with more stable quality in terms of bonding interface and performance [2]. As a consequence of the high processing temperature, the inter-diffusion of substitution elements between dissimilar materials, besides interstitial carbon diffusion from ferritic steel, takes place.

The bonding mechanism and the interface microstructure have been extensively researched: it was suggested that the elements diffusion occurring between base and clad material represents a possibly key to understanding the bonding formation between the two metals [14]. Experimental observations that were carried out on carbon steels clad with austenitic stainless steel $[15,16]$ showed microstructural changes that were associated with diffusion phenomena at the interface, highlighting how carbon diffusion from base to cladding material results in the formation of a decarburization layer at the carbon steel side and a copious carbide precipitation, with a significant local worsening of the corrosion resistance properties at the austenitic steel side.

In previous works [17], the microstructural changes at the cladding interface between low carbon steel (base material) and austenitic stainless steel (coating) in hot rolled plates were studied. In [18], the feasibility of welding this kind of plates by a single pass laser beam technique was experimented. In the work presented here, we carried out a metallurgical characterization of the interfaces in steel plates clad with various nickel alloys by hot rolling. The characterization has been based on the integration between the experimental investigations on the microstructural features, and a theoretical analysis of the effects due to the cladding parameters on diffusion depth and the interface characteristics. As base materials steels with low $(C=0.14 \%)$ or very low $(C=0.04 \%)$ carbon content were considered, as coating AISI 304 austenitic stainless steel, Alloy 59 with high Ni content or Monel $400 \mathrm{Ni}-\mathrm{Cu}$ alloy. With the purpose of evaluating the amplitude of the zone that is affected by microstructural changes, scanning electron microscopy (SEM) observations and microanalytical measurements by energy dispersive spectroscopy (EDS) were performed to detect the diffusion profiles of the substitution elements and measure the diffusion layer thickness. The mechanical properties near the interfaces were evaluated through Vickers microhardness measurements. The experimental profiles of the diffused elements across the bimetallic interface were fitted by a diffusion mathematical model that was based on the Gaussian error function, obtaining the couples of values of temperature and time, which are compatible with the production processes. Subsequently, the effects of process temperature variations on the thickness involved by diffusion were investigated.

\section{Materials and Methods}

\subsection{Clad Plates Production, Specimens Fabrication, and Experimental Tests}

Before the hot rolling process, clad alloy and base steel were both rolled separately to the desired thickness and then mechanically and chemical cleaned to remove any contaminations and oxide layers [19]. Two packs of base steel/cladding metal were assembled and symmetrically stacked by interposing a sheet of a ceramic insulating material. This package was surrounded with perimeter bars that were welded in order to build a hermetic closure and then evacuated by a vacuum pump; microstructure, chemical composition, and distribution of interface oxides inclusions can be related to 
the vacuum degree inside the symmetrically stacked package [20,21]. This package was hot rolled after being pre-heated above the recrystallization temperature [22]. The local contact points between base steel and cladding alloy undergo plastic deformation under the high rolling pressure [11], so their area gradually expands, interesting the entire bonding surface. Under these conditions, the diffusion of the alloying element occurs, giving rise to the bonding interface, whose thickness continues to grow during the permanence at high temperature [23].

The examined plates, furnished in the hot rolling conditions, were:

(a) low carbon steel ASTM A 515 Gr.60 plate (thickness $6.5 \mathrm{~mm}$ ), clad with AISI 304 L austenitic steel (thickness $2.5 \mathrm{~mm}$ ) (Table 1);

(b) low carbon steel ASTM A 283 plate (thickness $10 \mathrm{~mm}$ ), clad with Alloy 59 (thickness $2.5 \mathrm{~mm}$ ) (Table 2); and,

(c) low carbon steel AISI 1010 plate (thickness $13 \mathrm{~mm}$ ), clad with Monel 400 (thickness $2 \mathrm{~mm}$ ) (Table 3).

Table 1. Composition of low carbon steel and austenitic stainless steel (wt. \%).

\begin{tabular}{cccccccccccc}
\hline Materials & $\begin{array}{c}\text { Thick } \\
(\mathbf{m m})\end{array}$ & $\mathbf{C}$ & $\mathbf{M n}$ & $\mathbf{S i}$ & $\mathbf{P}$ & $\mathbf{S}$ & Al & $\mathbf{C r}$ & $\mathbf{N i}$ & $\mathbf{M o}$ & $\mathbf{F e}$ \\
\hline $\begin{array}{c}\text { Base material: } \\
\text { ASTM A515 } \\
\quad \text { Gr.60 }\end{array}$ & 6.5 & 0.14 & 0.85 & 0.20 & 0.008 & 0.001 & 0.04 & - & - & - & Bal. \\
\hline $\begin{array}{c}\text { Cladding: AISI } \\
\text { 304 L }\end{array}$ & 2.5 & 0.017 & 1.32 & 0.39 & 0.029 & 0.003 & - & 18.39 & 10.07 & - & Bal. \\
\hline
\end{tabular}

Table 2. Composition of ferritic steel and high Ni alloy (wt. \%).

\begin{tabular}{cccccccccccc}
\hline Materials & $\begin{array}{c}\text { Thick } \\
(\mathbf{m m})\end{array}$ & $\mathbf{C}$ & $\mathbf{M n}$ & $\mathbf{S i}$ & $\mathbf{P}$ & $\mathbf{S}$ & $\mathbf{A l}$ & $\mathbf{C r}$ & $\mathbf{N i}$ & $\mathbf{M o}$ & $\mathbf{F e}$ \\
\hline $\begin{array}{c}\text { Base material: } \\
\text { ASTM A283 }\end{array}$ & 10 & 0.040 & 0.52 & 0.24 & 0.009 & 0.0016 & 0.057 & 0.028 & 0.006 & 0.006 & Bal. \\
\hline $\begin{array}{c}\text { Cladding: } \\
\text { Alloy 59 }\end{array}$ & 2.5 & 0.005 & 0.15 & 0.040 & 0.004 & 0.002 & - & 22.85 & 59.47 & 15.55 & $<1.5$ \\
\hline
\end{tabular}

Table 3. Composition of low carbon steel and Ni-Cu alloy (wt. \%).

\begin{tabular}{cccccccccccc}
\hline Materials & $\begin{array}{c}\text { Thick } \\
(\mathbf{m m})\end{array}$ & $\mathbf{C}$ & $\mathbf{M n}$ & $\mathbf{S i}$ & $\mathbf{P}$ & $\mathbf{S}$ & Al & $\mathbf{C r}$ & $\mathbf{N i}$ & $\mathbf{C u}$ & $\mathbf{F e}$ \\
\hline $\begin{array}{c}\text { Base material: } \\
\text { AISI 1010 }\end{array}$ & 13 & 0.109 & 1.19 & 0.27 & 0.011 & 0.001 & 0.038 & 0.014 & 0.23 & 0.14 & Bal. \\
\hline $\begin{array}{c}\text { Cladding: } \\
\text { Monel 400 }\end{array}$ & 2 & 0.1 & 1.0 & 0.2 & - & 0.002 & - & - & 64.9 & 32.0 & 1.7 \\
\hline
\end{tabular}

SEM observations were carried out on samples in the as supplied conditions, cut from the hot rolled plates, and metallographically prepared by mechanical polishing and chemical etching. Nital reagent ( $2 \% \mathrm{HNO}_{3}, 98 \%$ ethyl alcohol) was used for carbon steel etching; the austenitic steel and the $\mathrm{Ni}$ alloy were etched, respectively, by Glyceregia $\left(16 \% \mathrm{HNO}_{3}, 42 \% \mathrm{HCl}, 42 \%\right.$ glycerol) and Kroll type reagent $\left(30 \mathrm{~mL} \mathrm{HNO}_{3}, 10 \mathrm{~mL} \mathrm{HF}, 50 \mathrm{~mL} \mathrm{H}_{2} \mathrm{O}\right)$; the Monel alloy was etched by Royal solution $(50 \mathrm{~mL}$ $\left.\mathrm{HNO}_{3}, 50 \mathrm{~mL} \mathrm{HCl}\right)$. The ASTM Test A262-Practice E highlighted the effects of carbide precipitation on the austenitic steel sensitization.

Energy Dispersive Spectroscopy (EDS), scanning the electron beam along lines orthogonal to the cladding interfaces, was utilized to perform concentration profiles. Mechanical properties were 
evaluated by Vickers microhardness test ( $25 \mathrm{~g}$ load, $10 \mathrm{~s}$ time) along the same direction orthogonal to the cladding interface.

\subsection{Theoretical Modelling and Simulation}

The experimental profiles of diffused elements across the clad interfaces were fitted by the theoretical formulation that was used for modeling the diffusion between two semi-infinite bodies characterized by different values of the starting concentration of the considered element. This phenomenon can be modelled by one of the particular solutions of the Fick's second law of diffusion, being expressed as [24]:

$$
c(x)=\left(\frac{c_{\mathrm{A}}+c_{\mathrm{B}}}{2}\right)-\left(\frac{c_{\mathrm{A}}-c_{\mathrm{B}}}{2}\right) \operatorname{erf}\left(\frac{\mathrm{x}}{2 \sqrt{D_{i} t}}\right)
$$

where $c(x)$ is the concentration along the diffusion direction, $c_{\mathrm{A}}$ and $c_{\mathrm{B}}$ are the starting concentrations in the two regions of diffusion A and B (all expressed in wt. \%), erf(Z) is the Gaussian error function, $x(\mathrm{~m})$ is the distance from the initial interface (Matano's interface), $t(\mathrm{~s})$ is the duration of the diffusion transient, and $D_{i}\left(\mathrm{~m}^{2} / \mathrm{s}\right)$ is the interdiffusion coefficient.

In case the substitution alloying element concentration at $t=0$ is negligible in region $B\left(c_{B}=0\right)$, while the solvent concentration is predominant in the same region, at a first approximation, the interdiffusion coefficient $D_{i}$ can be assumed to be equal to the diffusion coefficient $\mathrm{D}$ of the considered diffusing element in dilute solution, which can be expressed as a function of the absolute temperature $T$ by the Arrhenius type equation [24]:

$$
D=D_{\mathrm{o}} \mathrm{e}^{-\frac{Q}{R T}}
$$

where $Q(\mathrm{~J} / \mathrm{mol})$ is the activation energy, $\mathrm{R}=8.3144 \mathrm{~J} / \mathrm{mol} \cdot \mathrm{K}$ the gas constant, $D_{\mathrm{o}}\left(\mathrm{m}^{2} / \mathrm{s}\right)$ the pre-exponential factor, and $\mathrm{T}$ is the absolute temperature $(\mathrm{K})$.

The fittings of the theoretical curves on the experimental profiles have been performed by a non-linear least squares approach, searching for the value of the parameter $D \cdot t$, in the argument of the Gaussian error function $\operatorname{erf}(Z)$, which minimizes the sum of the squared distances between the concentration profiles obtained by EDS as reference curves, and the theoretical ones that are expressed by Equation (1). For this purpose, being the search for the solution a non-convex problem, an evolutionary solving tool has been used.

The theoretical curves, as fitted on the experimental profiles, have been further validated by the results of PanDiffusion, a module of Pandat ${ }^{\mathrm{TM}}$ v2019.1 software (CompuTherm LLC, Middleton, WI, USA) that was specifically developed to simulate one-dimensional diffusion under a variety of conditions, and already used in the characterization of diffusion bonding [25].

The parameter $D \cdot t$ is particularly significant in cladding process. It can be meant as a concentration profile shape factor, since it characterizes the shape of the concentration curve that is expressed by Equation (1), its slope across the Matano interface and, therefore, the diffusion depth, which determines the width of bonding at the interface. The latter aspect has a direct impact on the efficiency of the interface in terms of mechanical stability, being a strong interface bonding generally attributed to a sufficient alloying elements diffusion: the wider the diffusion depth is, the stronger the interfacial shear strength of clad plates will be [26], as a result of the interaction among atoms of the different elements in solid solution.

Furthermore, from the diffusion modelling point of view, the same parameter $D \cdot t$ governs the relationship between the diffusion bonding time and temperature: known the experimental value of $D \cdot t$, and set the duration of the diffusion transient $(t)$, the value of diffusivity $(D)$, which is required to obtain the specific shape of the diffusion curve parameterized by $D \cdot t$, can be directly calculated; then, the corresponding diffusion temperature, being considered as an equivalent temperature $\left(T_{\text {eq. }}\right)$ constant during all the diffusion transients, can be estimated by the Arrhenius type Equation (2), if the characteristics of the diffusing element and diffusion region are known. 
In summary, coupling the results of experimental-theoretical fittings (values of parameter $D \cdot t$ ) with Equation (2) for the diffusion coefficient $D$, and the literature data for pre-exponential factor $D_{\mathrm{o}}$ and activation energy $Q$, it is possible to:

- obtain the couples of values of temperature and time, which are compatible with the process, and characterize the diffusion phenomena; and,

- analyze the effects of process temperature and time variations on the thickness involved by diffusion and on cladding uniformity and stability.

\section{Results of Experimental Characterization}

\subsection{ASTM A515 Gr.60 Low Carbon Steel Clad with AISI 304L Austenitic Stainless Steel}

The interface between base and clad material is represented by a thin, but clearly identifiable, line that follows the ferritic grains profile, as shown by the SEM micrograph in Figure 1. In agreement with the investigations carried out in literature [5,13], at the carbon steel side, close to the cladding material, we found a decarburized zone with a thickness of about $120 \mu \mathrm{m}$, consisting of coarse ferritic grains $(30-50 \mu \mathrm{m})$; away from the cladding line, it is observable the typical rolling microstructure, with pearlitic grains being aligned according to parallel bands.

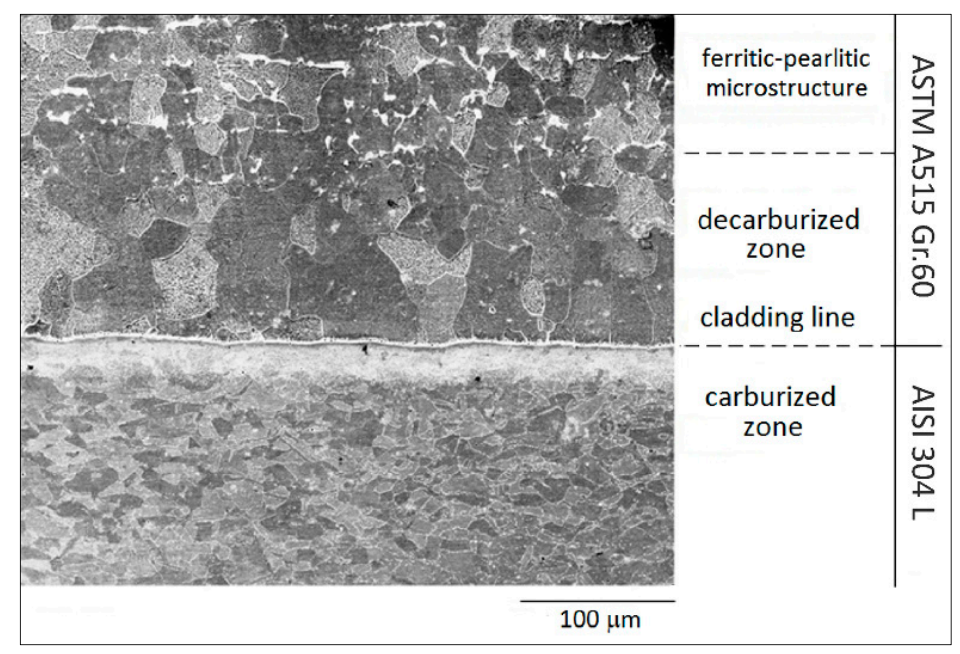

Figure 1. ASTM A515 Gr.60/AISI 304 L interface.

Carbon and substitution elements give rise to diffusion profiles trough the interface between base and cladding metal due to their compositional gradients. Carbon atoms migrate from the base metal towards the austenitic steel, where they accumulate at grain boundaries, giving rise to $\mathrm{Cr}$ carbide formation in the sensitization temperature range. The SEM micrographs in Figure 2, which were taken on the austenitic side near the interface, show a zone with an overall width of about $300 \mu \mathrm{m}$ that is characterized by a copious carbide precipitation at grains boundaries, as a consequence of carbon diffusion. Immediately close to the cladding line, grains appear to be strongly elongated; moving away from it, carbides precipitation decreases and the austenitic grains assume a more regular morphology. In the zone of carbide precipitation, the typical microstructure of rolled austenite indicates that recrystallization after hot working did not occur.

FM-1e Vickers microhardness tester (Future Tech Corp, Kawasaki, Japan) was used to measure carbide precipitation hardening effect. When considering that the average hardness measured in the austenitic and carbon steel is, respectively, around 220 and $180 \mathrm{HV}$, Vickers surveys, carried out along lines orthogonal to the cladding interface, showed a peak of about $350 \mathrm{HV}$ at the austenitic carburized side, while, at the base material, decarburized side hardness decreases down to $150 \mathrm{HV}$ (Figure 3). 

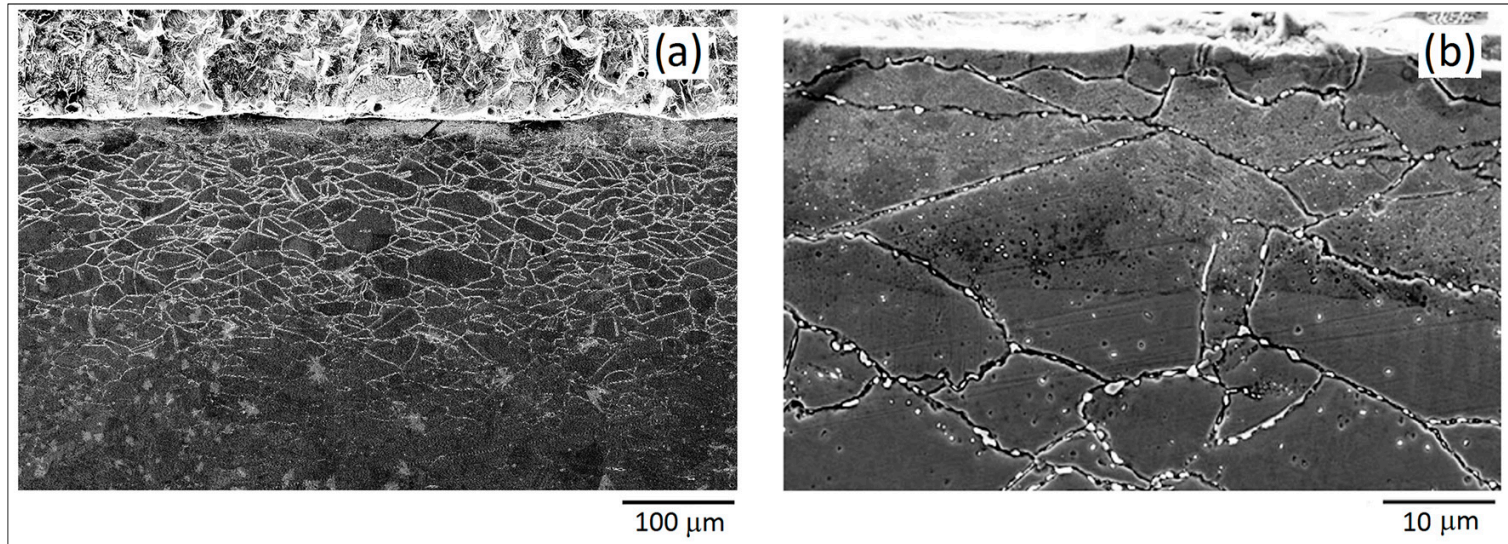

Figure 2. Austenitic steel side: (a) zone of carbide precipitation, (b) detail of the austenitic deformed grains close to the cladding line.

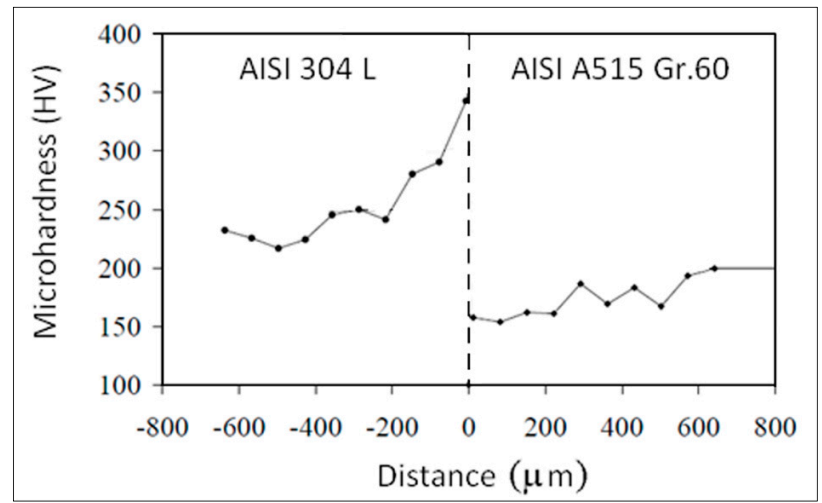

Figure 3. The results of Vickers microhardness test along a transversal line to the interface ASTM A515 Gr.60/AISI 304 L.

The substitution alloying elements moved in the direction opposite to carbon, leading to a graded interface with different microstructures. Figure 4 shows the concentration profiles of nickel and chromium that were obtained through EDS measurements: the zone that is involved in diffusion of these elements has a width of about $10 \mu \mathrm{m}$ (a very short length as compared to carbon diffusion). The initial position of the interface is indicated by the dashed line, which was located on the basis of the Matano's condition.

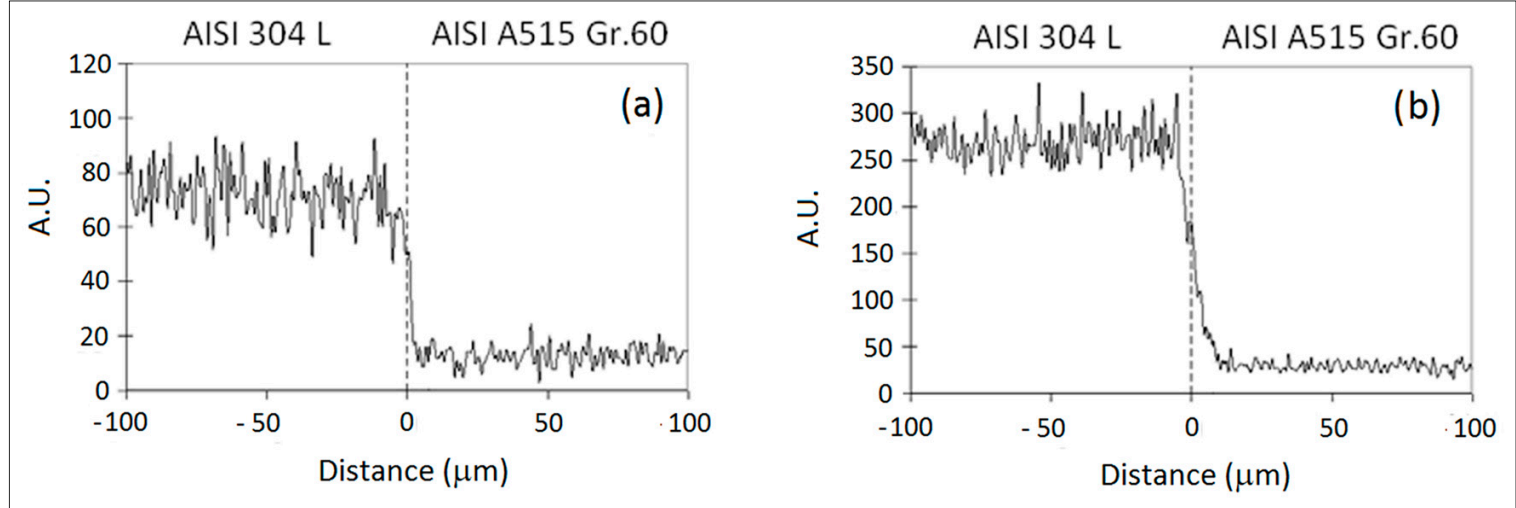

Figure 4. Results of energy dispersive spectroscopy (EDS) measurements along a line orthogonal to the interface ASTM A515 Gr.60/AISI 304 L. Concentration profiles according to the distance from the initial interface: (a) $\mathrm{Ni},(\mathbf{b}) \mathrm{Cr}$. 
Inside the cladding line, it is possible to distinguish the interface between the large ferritic grains and the deformed austenitic grains. Figure 5 shows a detail of the cladding interface after glyceregia etching specific for austenitic steel. In this micrograph, the boundary of a ferritic grain, located across the interface, has been marked in white: a part of this grain does not result in being affected by etching, because of the enrichment of chromium that comes from the austenitic side.

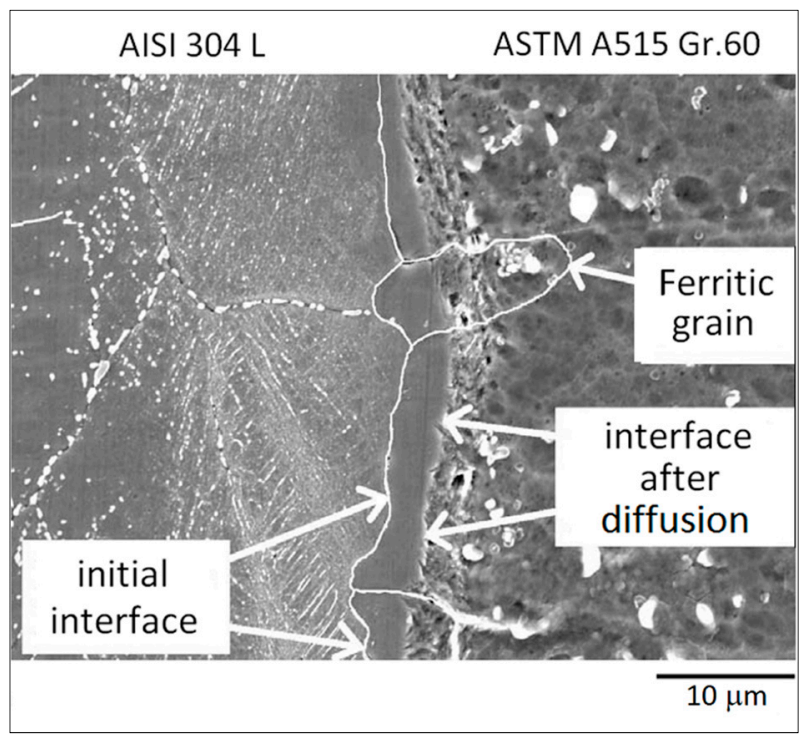

Figure 5. Labelled scanning electron microscopy (SEM) micrograph of the austenitic/ferritic interface.

It is interesting to note that carbon diffusion in the austenitic steel takes place as soon as bonding begins; therefore, it is reasonable to assume that the interface with the carburized zone coincides with the initial interface between the two steels.

Moreover, our observations lead to considering that a backing of the ferritic phase from its initial position occurred, which was caused by diffusion of the substitution elements. In fact, following the boundaries of the ferric grains, it is possible to outline, in white, the initial position of the interface, while its position after diffusion appears to be translated of some microns towards the base steel.

Therefore, we addressed our experiments to characterize the phases in the zone that were crossed by the interface displacement: punctual EDS measurements were performed across this zone (Figure 6a) and the obtained compositions are reported on the WRC-92 diagram [27,28] (Figure 6b).

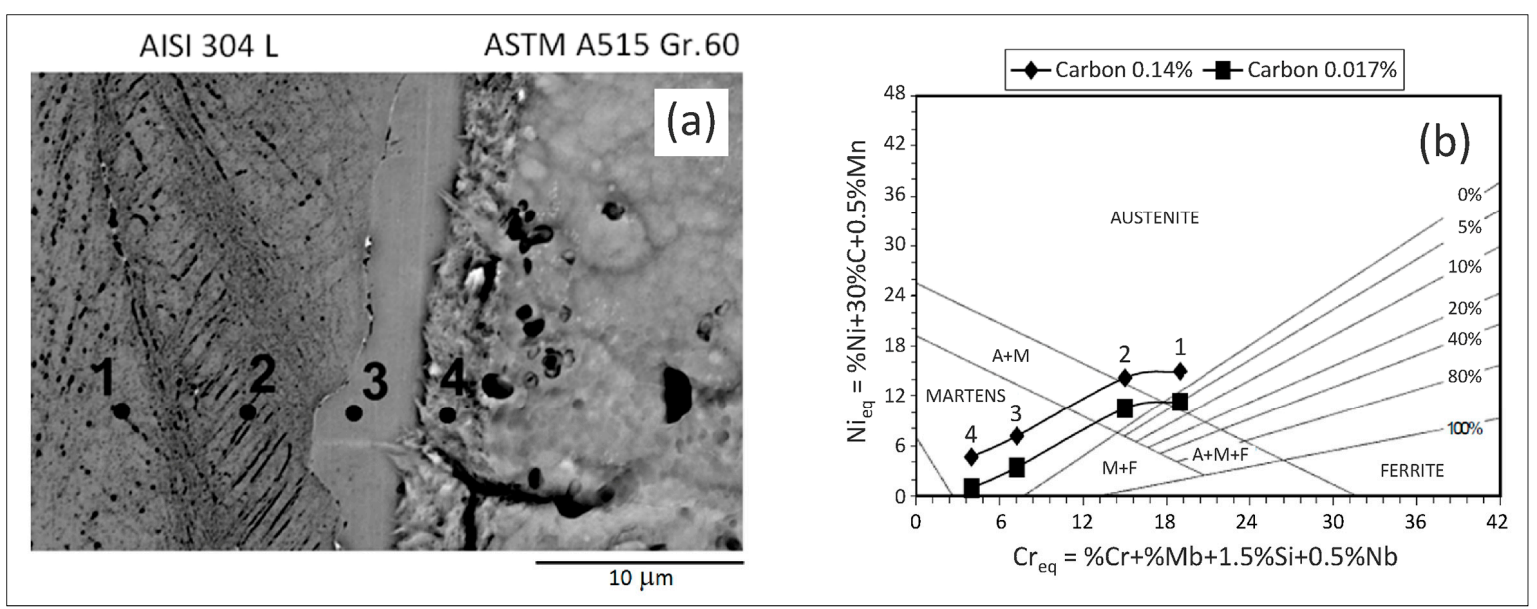

Figure 6. Results of punctual EDS measurements at the austenitic/ferritic interface: (a) SEM micrograph with indication of four points; and, (b) WRC-92 diagram utilized for phase identification. 
For each point, two extreme conditions have been considered: carbon content negligible ( $C=0.017 \%$ ), under the assumption that carbon predominantly contributes to the carbide formation, and carbon equal to the base steel nominal composition $(C=0.14 \%)$. Points No. 1 and 2 are respectively in the austenitic and austenitic/martensitic field of the WRC-92, while points No. 3 and 4, located across cladding line, can be considered to be martensitic, as it can be seen in Figure $6 \mathrm{~b}$.

In the zone that was affected by carbide precipitation, chromium depletion near the grain boundaries results in the austenite sensitization to the intercrystalline corrosion, as highlighted by the micrograph in Figure 7 that was taken after having carried out the ASTM Test A262-Practice E (the box with the higher magnification highlights the corrosion effects in a zone immediately close to the cladding line). Anyway, the thickness of the sensitized zone is very much lower than that of the cladding layer.

This check is very important, because the lowest fracture toughness, corrosion resistance, and short fatigue lifetime characterize the carburized layer; conversely, fracture under shear stress condition is easy to occur in the decarburized layer [19,29].

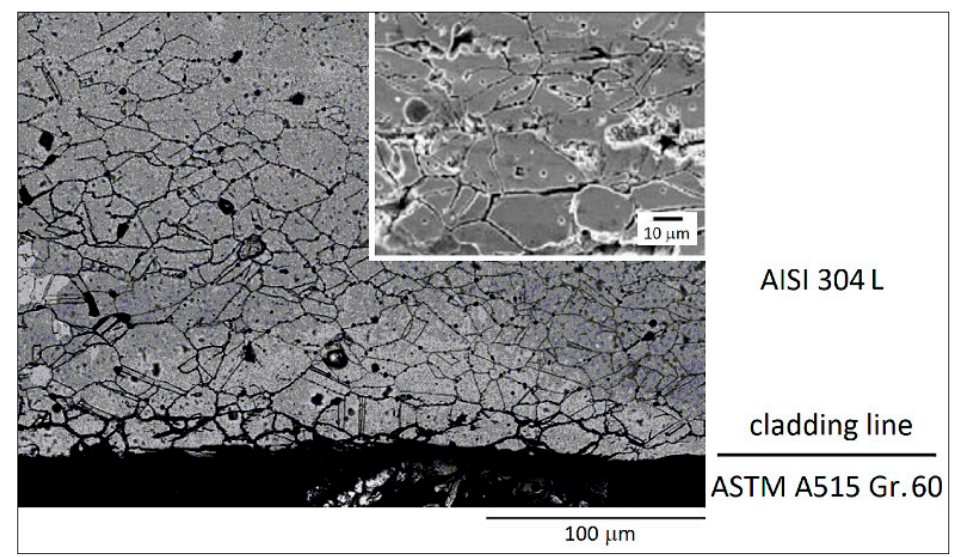

Figure 7. Sensitized region at the austenitic side near the cladding line (ASTM Test A262-Practice E).

\subsection{ASTM A283 Extra Low Carbon Steel Clad Alloy 59}

Additionally, in this case, a thin line that follows the ferritic grains boundaries represents the interface between base and clad material (Figure 8). At the ferritic steel side, for a width of about $150 \mu \mathrm{m}$ starting from the cladding line, the grains underwent a slight coarsening.

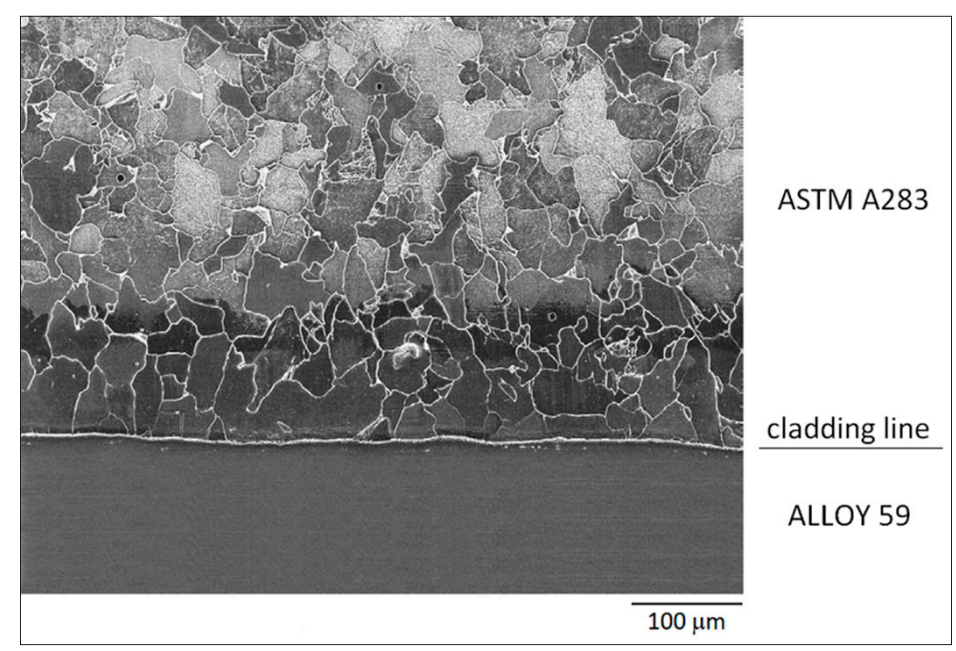

Figure 8. ASTM A283/Alloy 59 interface. 
Small austenitic grains with no evidence of carbide precipitation, as shown by SEM observation (Figure 9) performed after etching by the Kroll type reagent that dissolved the ferritic steel, characterize the structure of the Alloy 59 near the cladding interface.

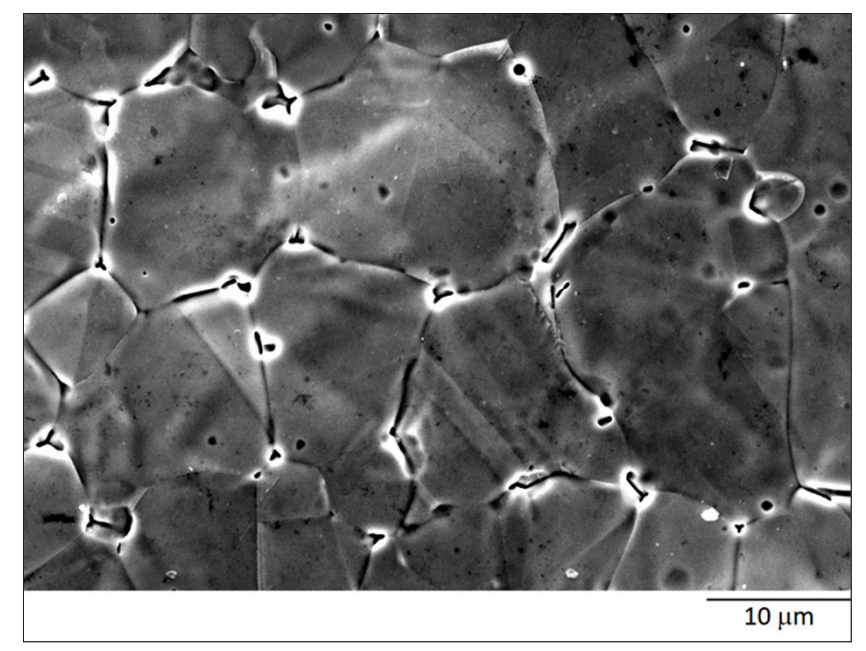

Figure 9. Microstructure of the Alloy 59.

The microhardness profiles of the two materials, Alloy 59 (average hardness $260 \mathrm{HV}$ ) and ASTM A283 steel (average hardness $150 \mathrm{HV}$ ), do not show any significant variations near the cladding interface (Figure 10). In fact, for the negligible carbon content of the base steel, there is no precipitation of carbides in the cladding alloy and, consequently, local hardening is absent.

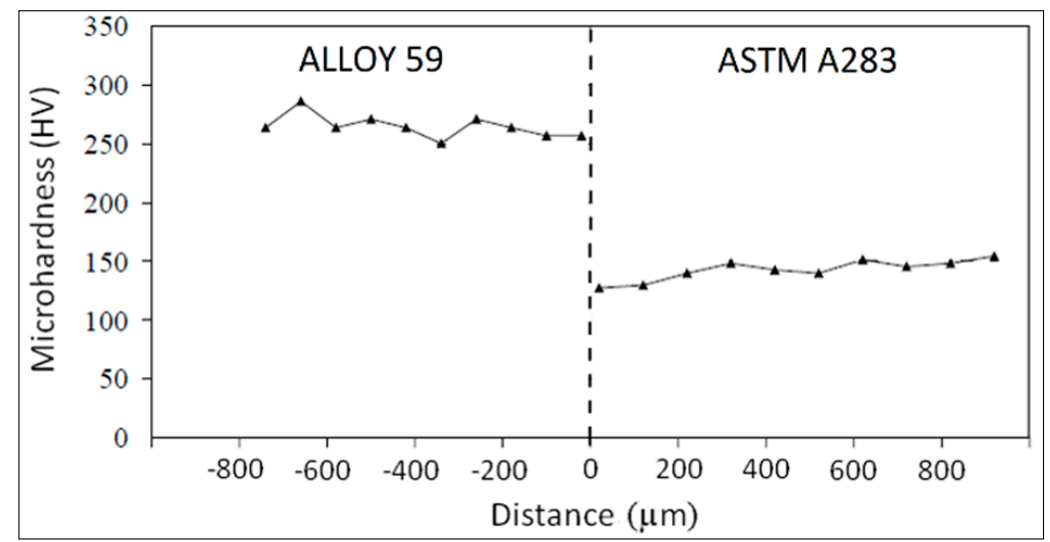

Figure 10. The results of Vickers microhardness test along a transversal line to the interface ASTM A283/Alloy59.

It is evident the alloying element inter-diffusion from cladding layer towards base material, while iron diffused in the opposite direction, due to the different concentrations of the two materials. The extent of the area affected by diffusion makes it possible to observe that cladding line (indicated by the grey band in Figure 11) shifted towards the base steel from the initial position of the interface (dashed line), calculated through the Matano's condition: the zone between them has been identified as austenitic by means of punctual EDS measurements, while the martensitic phase is present close to the grey band. 

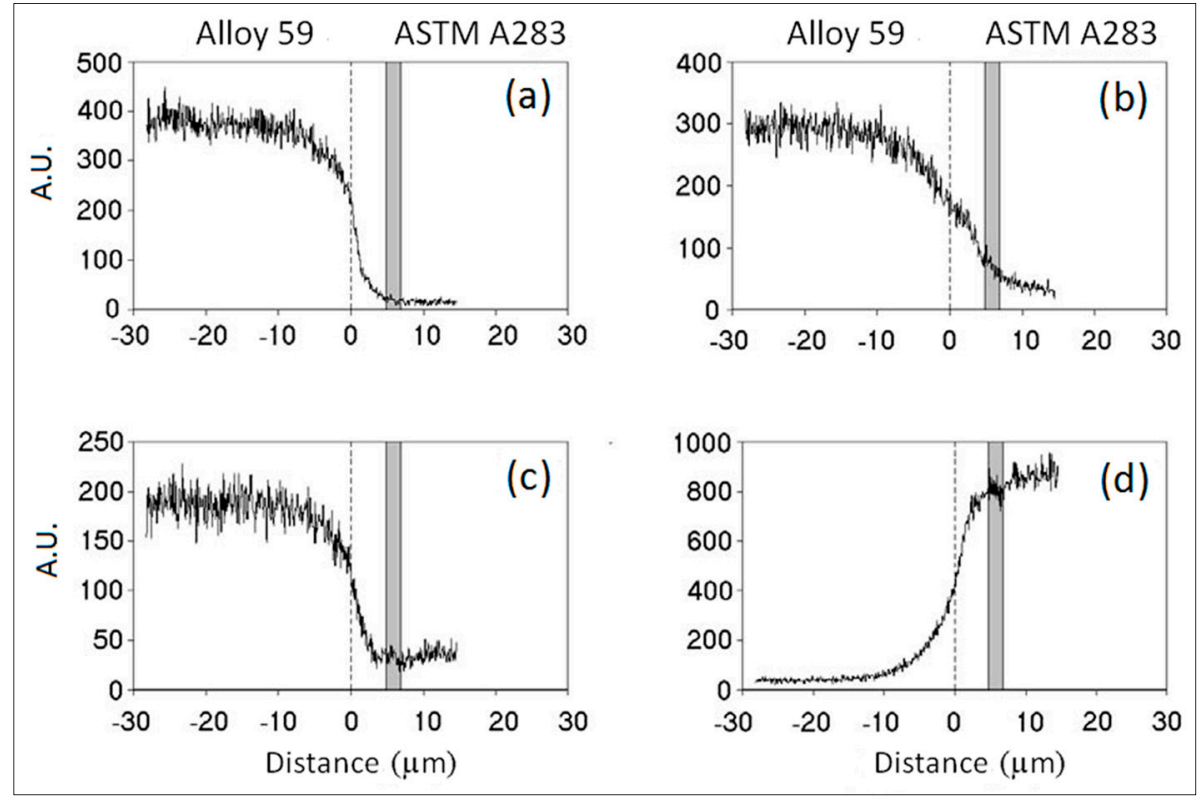

Figure 11. Results of EDS measurements along a line orthogonal to the interface ASTM A2830/Alloy 59. Concentration profiles vs. the distance from the initial interface: (a) Ni; (b) Cr; (c) Mo; and, (d) Fe.

\subsection{AISI 1010 Low Carbon Steel and Monel $400 \mathrm{Cu}-\mathrm{Ni}$ Alloy}

The interface is represented by a thin but clear line, which follows the boundaries of the ferritic-pearlitic grains, as in the previous cases (Figure 12). The base steel shows the typical rolling microstructure, without evidence of decarburization phenomena; in a zone that is close to the cladding line, for a width of about $200 \mu \mathrm{m}$, the Monel alloy is characterized by non-recrystallized grains of small size.

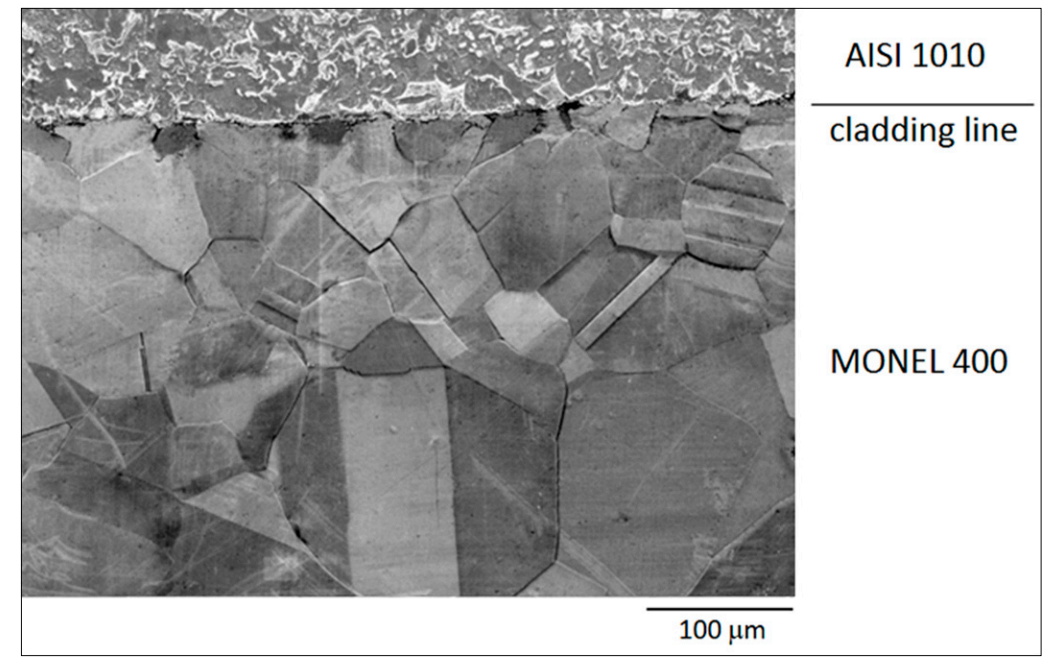

Figure 12. AISI 1010/Monel 400 interface.

Figure 13 gives the Vickers microhardness profile according to the distance from the cladding line: at the Monel alloy side, we observe almost constant values around $180 \mathrm{HV}$, while the steel microhardness is about $150 \mathrm{HV}$.

Figure 14 shows the concentration profiles of $\mathrm{Ni}, \mathrm{Cu}$, and $\mathrm{Fe}$, which are obtained through EDS measurements, with an indication of the initial interface or Matano's interface (dashed line) and the cladding line (grey band). The inter-diffusion of the substitution elements involves a small zone wide about $20 \mu \mathrm{m}$. In particular, the presence of Ni makes $\mathrm{Cu}$ soluble in this restricted zone of the base steel. 
Moreover, the inter-diffusion of $\mathrm{Ni}$ and $\mathrm{Cu}$ towards the base steel and Fe in the opposite direction causes, also in this case, a displacement of the cladding line towards the base steel, with respect to the initial interface position that the Matano's condition can determine.

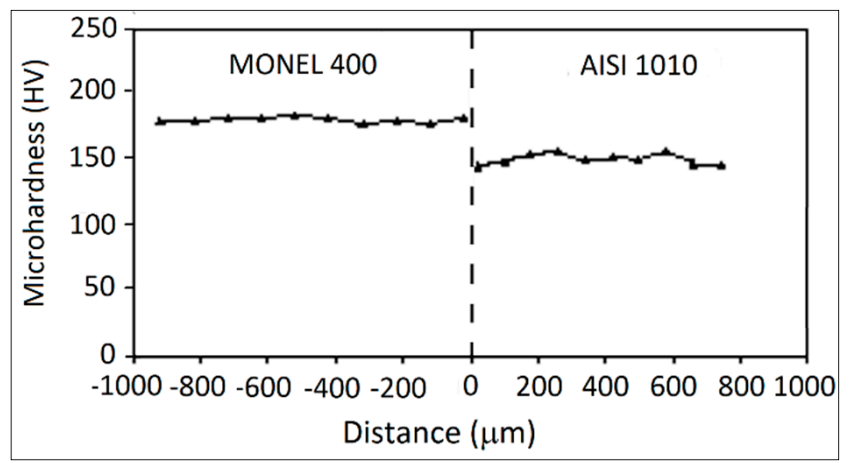

Figure 13. Results of Vickers microhardness test along a line orthogonal to the interface AISI 1010/Monel 400.
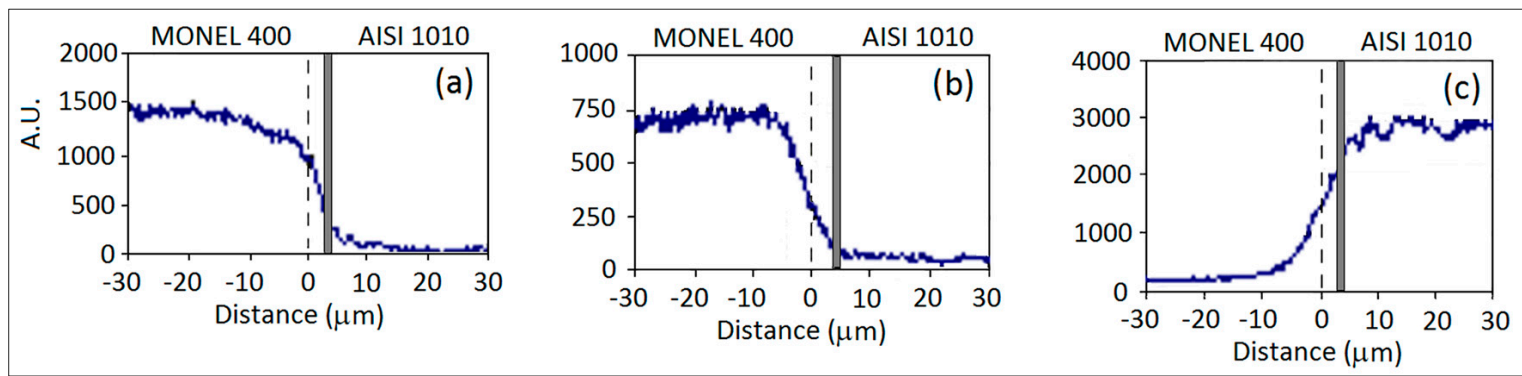

Figure 14. Results of EDS measurements along a line orthogonal to the interface AISI 1010/Monel 400. Concentration profiles: (a) $\mathrm{Ni}$; (b) $\mathrm{Cr}$; (c) Fe.

\section{Results of Theoretical Simulation and Discussion}

The experimental profiles of the solute atoms across the bimetallic interfaces have been fitted by the procedure that is reported in the previous Section 2.2. Equation (1) characterizes the element transport controlled by solid state diffusion according to the Fick's second law, so it expresses the theoretical concentration profiles. Assuming that the diffusivity does not change with concentration, it is possible to calculate the $D \cdot t$ parameter in Equation (1) that gives a good fit of the EDS experimental profiles, as shown in Figure 15 for Ni diffusion at the interface ASTM A515 Gr.60/AISI 304 L.

To perform the fitting, preliminarily the starting concentration in the two diffusion regions, which correspond to the cladding alloy and the base steel, must be fixed according to the reference values in Table 1 (10.07 and $0 \mathrm{wt}$. \%, respectively), for both the experimental profile obtained by EDS and the theoretical one to be drawn by Equation (1). In the first case, this means imposing the average values of the concentrations measured experimentally in arbitrary units (A.U.), in the portions of the two regions that are not affected by the diffusion process, equal to the reference values. In the second case, it consists in imposing the reference values to the two plateaus on the theoretical profile, that is $c_{\mathrm{A}}=10.07$ and $c_{\mathrm{B}}=0 \mathrm{wt}$. \% in Equation (1).

By means of this preliminary setting, it is possible to couple the experimental curve, and the theoretical one that will fit the former, even though they are expressed in different measure units (A.U. and wt. \%, respectively). 


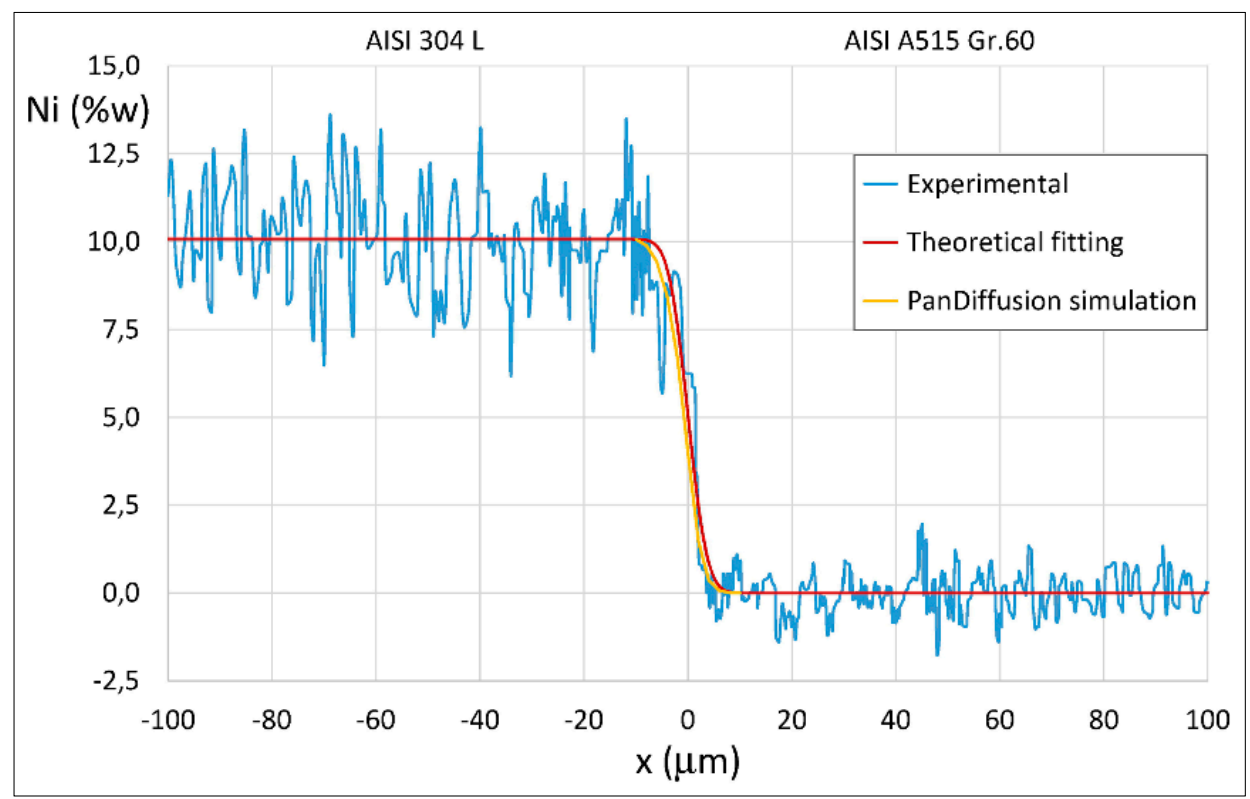

Figure 15. Experimental and calculated concentration profiles along a line orthogonal to the interface ASTM A515 Gr.60/AISI 304 L.

The theoretical fitting has been optimized by minimizing the sum of the squared distances between the experimental curve (Figure 4a, and Figure 15 blue line) and the theoretical curve (Figure 15 red line), as calculated by means of Equation (1) within the interval outside the two plateaus of starting concentrations, obtaining a value of parameter $D \cdot t=4.24 \times 10^{-12} \mathrm{~m}^{2}$. The fitting has been performed by the evolutionary solving tool that was implemented in Excel, while assuming the sum of the squared distances between the experimental and theoretical curves as the fitness function of the algorithm, and the parameter $D \cdot t$ as the variable of the optimization problem. The algorithm showed a uniform convergence to stable solution (convergence parameter 0.0001 ), also as the main genetic parameters change (population size $100 \div 150$, mutation rate $0.2 \div 0.5$, variable seeding factor), and allowed to obtain a fitting solution with a coefficient of determination $R^{2}=0.956$. Furthermore, the solution has been validated by the Pandat ${ }^{\mathrm{TM}}$ diffusion simulator module (PanDiffusion), which provided a diffusion curve (Figure 15 yellow line) that was substantially superimposable on the fitted theoretical one.

As stated in advance (Section 2.2.), in general terms, the parameter D.t expresses the shape factor of the diffusion profile, since it characterizes the trend of concentration in the diffusion transient and its slope across the Matano interface and, therefore, the diffusion depth, which determines the width of bonding in the direction orthogonal to the interface. Particularly, the value of the parameter $D \cdot t$ previously obtained, allows for analytically modeling the diffusion of $\mathrm{Ni}$ experimentally detected at the interface, so as to investigate the possible combination of temperature and time of the rolling process, which are not always made known by the producers, and the effect of their variations and instabilities on cladding.

By means of the fitting value of parameter $D \cdot t$, setting some values of time $(t)$, the corresponding values of diffusivity $(D)$ can be fixed, and while using Equation (2) with $D_{\mathrm{o}}=3.00 \times 10^{-4} \mathrm{~m}^{2} / \mathrm{s}$ and $Q=314 \mathrm{~kJ} / \mathrm{mol}$ for Ni diffusion in $\gamma$-Fe [30], the corresponding equivalent temperatures $\left(T_{\text {eq. }}\right)$ can be calculated, to be considered as constant during the diffusion transient. Table 4 gives the resulting couples of $T_{e q}$. and $t$ for Ni diffusion at the interface ASTM A515 Gr.60/AISI $304 \mathrm{~L}$, together with values of the diffusion coefficient $\mathrm{D}$. 
Table 4. Parameter $D \cdot t$ fitting value, analysed couples of $t$ and $T_{\text {eq., }}$ and corresponding values of $D$, for Ni diffusion at the interface ASTM A515 Gr.60/AISI 304 L.

\begin{tabular}{|c|c|c|c|}
\hline$D \cdot t\left(\mathrm{~m}^{2}\right)($ Exp/Fitted $)$ & $t$ (s) (Set Values) & $\mathrm{D}\left(\mathrm{m}^{2} / \mathrm{s}\right)$ (Calculated) & $T$ (K) (Calculated) \\
\hline $4.24 \times 10^{-12}$ & 3600 & $1.18 \times 10^{-15}$ & 1438 \\
\hline $4.24 \times 10^{-12}$ & 3000 & $1.41 \times 10^{-15}$ & 1448 \\
\hline $4.24 \times 10^{-12}$ & 2400 & $1.77 \times 10^{-15}$ & 1461 \\
\hline $4.24 \times 10^{-12}$ & 1800 & $2.36 \times 10^{-15}$ & 1477 \\
\hline
\end{tabular}

For each duration of the diffusion transient, the sensitivity of the diffusion phenomena to temperature has been investigated. Figure 16 shows the dependence of the $D \cdot t$ parameter on temperature with regards to the four diffusion times set in Table 4, and highlights how the shorter is the duration of the diffusion transient, and the lower is the value of $D \cdot t$, the higher is the robustness of the diffusion processes and cladding features to temperature fluctuations. This is due to the different slopes of the curves: the higher is the slope, the higher the effect of temperature variations on the $D \cdot t$ parameter, which is on the shape of diffusion curve, on diffusion depth, and subsequently on the width and properties of the bonding at the interface.

With regard to the interface ASTM A515 Gr.60/AISI 304 L examined here, the sensitivity of Ni diffusion curve and depth to the temperature variations can be quantified by the values of the slopes at the points corresponding to $D \cdot t=4.24 \times 10^{-12}$; these values, as calculated by the derivative of $D \cdot t$ with respect to temperature at $T=T_{\text {eq }}$. for the four diffusion times, are reported in the same Figure 16.

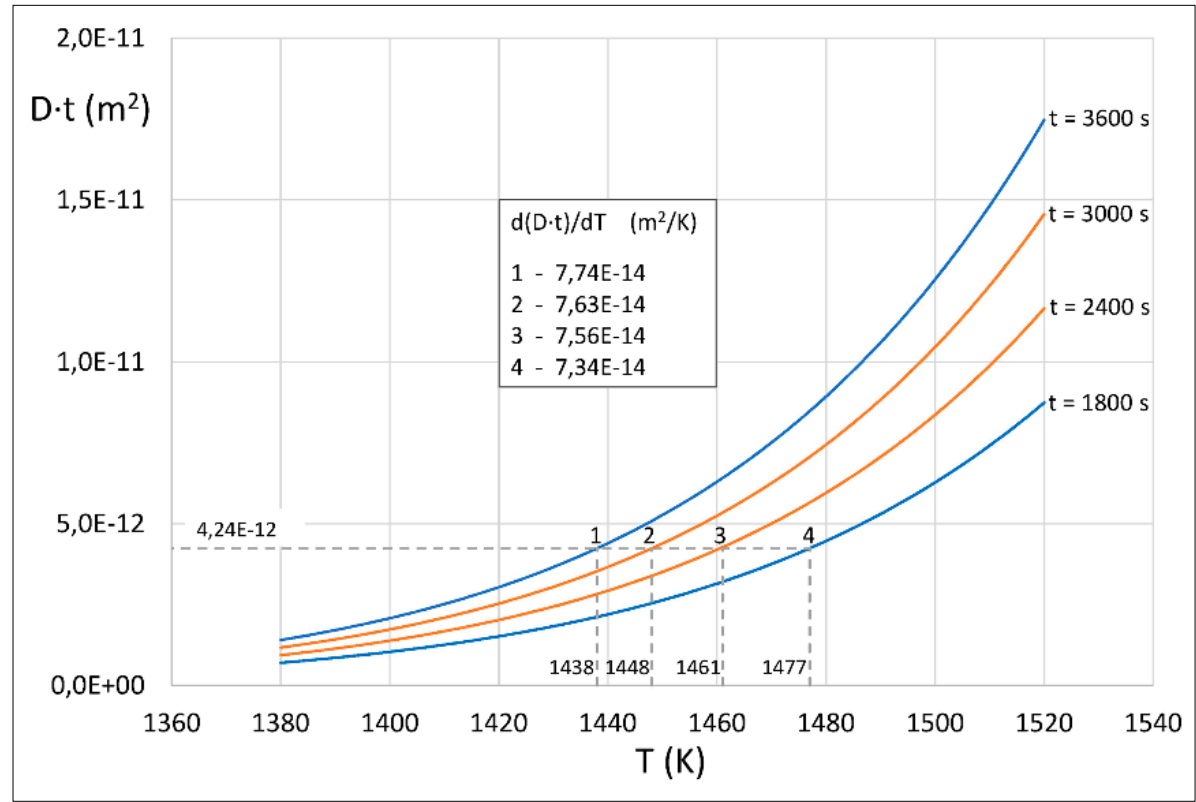

Figure 16. Trends of parameter $D \cdot t$ vs $T$ for different values of diffusion transient duration.

This theoretical approach to interface characterization allows for assessing the robustness of its main properties to temperature fluctuations, which can occur during rolling processes.

Being the diffusion process, the more influenced by temperature variation, the longer the duration of the diffusion transient, in order to emphasize the effects of process temperature fluctuations, $t=3600 \mathrm{~s}$ has been assumed. Figure 17 shows some diffusion profiles that are simulated for different values of temperature fluctuations around the equivalent value (1438 K). 


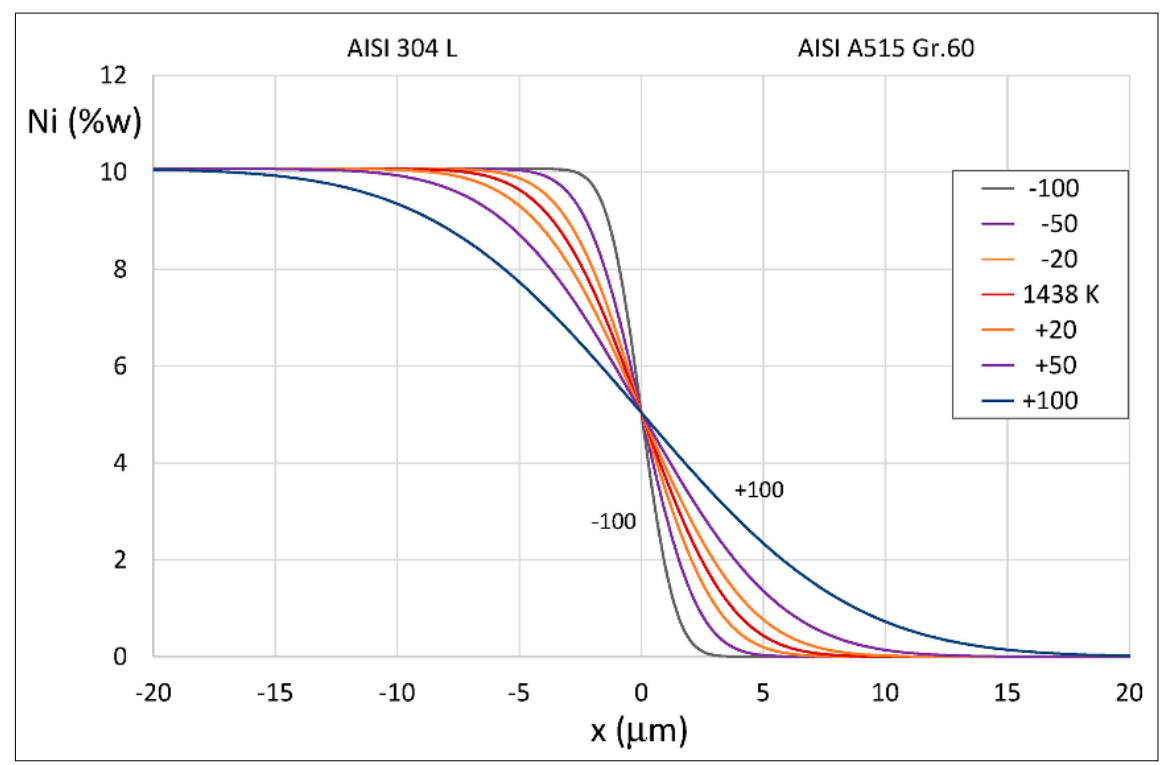

Figure 17. Concentration profiles of nickel along a line orthogonal to the interface ASTM A515 Gr.60/AISI $304 \mathrm{~L}$ calculated for different fluctuations of $T_{\text {eq. }}(t=3600 \mathrm{~s})$.

Due to these fluctuations, the value of diffusivity $D$ changes, and the same does the parameter $D \cdot t$ (being $t$ fixed), with the consequent variation of the slope and depth of the diffusion transient, and therefore of the width of the zone involved in Ni diffusion, which deviates significantly from the experimental value of $10 \mu \mathrm{m}$ when temperature changes starting from $50 \mathrm{~K}$, in particular for positive fluctuations.

As highlighted before, an interface bonding effective in terms of mechanical stability is generally attributed to a sufficient alloying elements diffusion, being the interfacial shear strength of clad plates as stronger as thicker is the diffusion distance. Consequently, while positive fluctuations have a beneficial effect from the point of view of bonding strength, negative fluctuations can significantly reduce it.

With regard to the effect of the diffusion time, process settings that provide longer transient durations results are more effective for high bonding strength, since, on the contrary, their reduction tends to compress the diffusion depth. This conflicts with the beneficial effect that shorter diffusion transients have in terms of the robustness of the diffusion processes to temperature fluctuations, which can make the bonding process more uniform.

Furthermore, too deep carbon diffusion might lead to detrimental effects that are caused by the formation of decarburized and carburized layers. In this case, the main problem is to avoid carbide precipitations at the grain boundaries. Equation (1) has been used to theoretically simulate carbon diffusion from base steel to cladding austenitic steel, but, while taking into account that $C$ diffusion in the $\gamma$-range is strongly concentration-dependent, its diffusivity D cannot be assumed constant varying the concentration. Therefore, the relation for $\mathrm{D}$ as a function of temperature and molar fraction that was proposed by Agren [31] has been used, assuming $T=T_{\text {eq. }}$ and iterating the calculation of $c(x)$ by Equation (1), so to take into account the effect of carbon content variation on its diffusivity along the diffusion direction. In this way, concentration profiles that have been simulated at various temperatures and diffusion times have been obtained, such as those shown in the Figure 18.

Actually, these profiles are characterized by high penetration depths (even at temperature lower than 100 degrees of the equivalent one), but luckily the time that is required to carbide precipitation grows considerably with a decrease of carbon content. Referring to the diagram TTS (Time Temperature Sensitisation) shown in [32], the time of $1 \mathrm{~h}$, which is required for sensitisation at $600{ }^{\circ} \mathrm{C}$ when $\mathrm{C}=0.042 \%$, becomes equal to $10 \mathrm{~h}$ when $\mathrm{C}=0.03 \%$. Obviously, this time is too long for carbide precipitation to occur during the cooling stage of plates after hot rolling. This explains why the hardening effect due to carbide precipitation was detected up to a depth of about $450 \mu \mathrm{m}$ (Figure 3). 
In any case, as for the diffusion of $\mathrm{Ni}$, also for that of $\mathrm{C}$, it occurs that the decrease in the diffusion transient duration results in a compression of the diffusion depth, as shown in Figure 18, where this effect is highlighted for the two extreme diffusion condition $\left(t=3600 \mathrm{~s}\right.$ and $T_{\text {eq. }}=1438 \mathrm{~K}$, solid lines; $t=1800 \mathrm{~s}$ and $T_{\text {eq. }}=1477 \mathrm{~K}$, dashed lines), and the corresponding temperature fluctuations more severe $( \pm 100 \mathrm{~K})$.

The previous observations, as a whole, allow for completing the interpretation of the parameter $D \cdot t$. As a concentration profile shape factor, it determines the diffusion depth and the bonding width; moreover, it governs the relationship between diffusion time and temperature, which, on the basis of the previous evidences, must be appropriately set to obtain a well-balanced compromise between bonding strength and uniformity, and metallurgical stability. Therefore, it is possible to conclude that $D \cdot t$ acts as a diffusion bonding efficiency parameter.

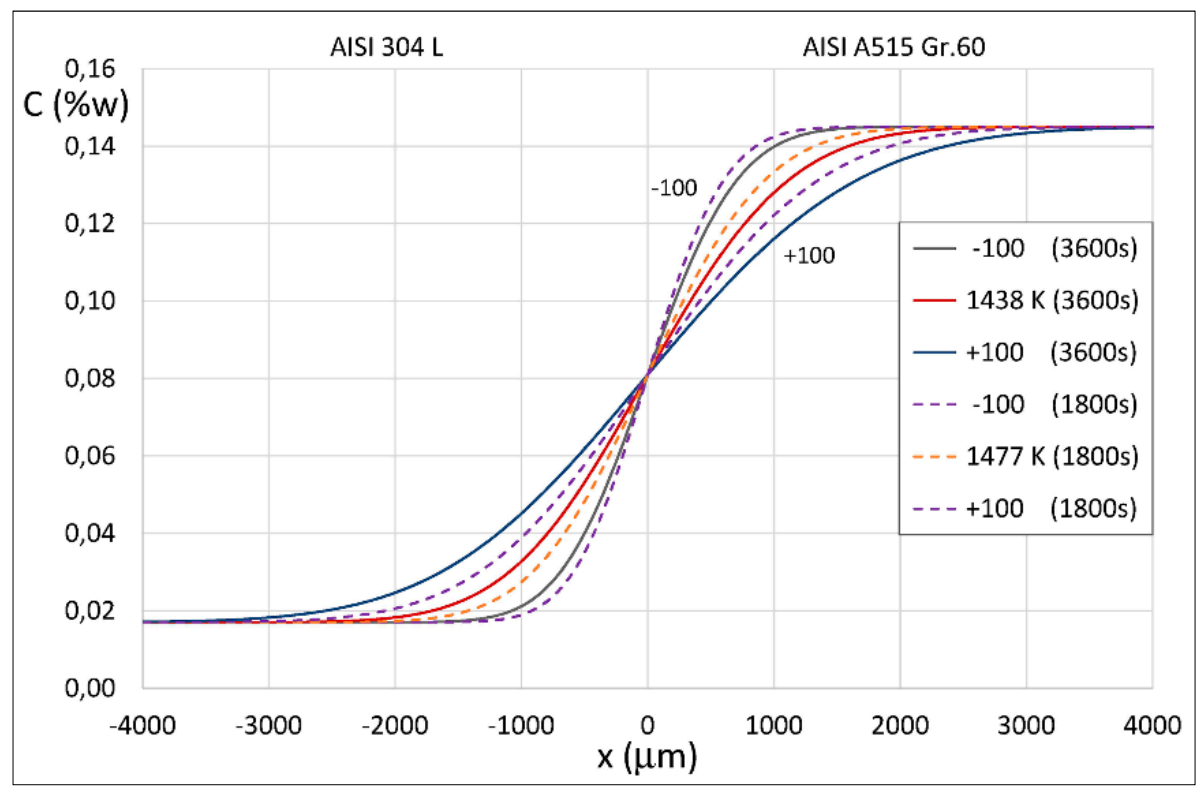

Figure 18. Concentration profiles of carbon along a line orthogonal to the interface ASTM A515 Gr.60/AISI 304L calculated for $\pm 100 \mathrm{~K}$ fluctuations of $T_{\text {eq. }}$ : comparison between $t=3600 \mathrm{~s}$ and $t=1800 \mathrm{~s}$.

The experimental profiles of the solute atoms across the bimetallic interfaces have been fitted and validated for the other two interfaces analysed, ASTM A283/Alloy 59 and AISI 1010/Monel 400, according the same procedure of Section 2.2. Additionally, in these two other cases, as for ASTM A515 Gr.60/AISI 304 L interface, before to perform the fitting, the starting concentration in the diffusion regions, which correspond to the cladding alloy and the base steel, have been set to the reference values of the diffusing element (reported in Tables 2 and 3), to preliminarily couple the experimental profiles and the theoretical ones that will fit them. By fitting the EDS profiles for Ni diffusion (Figures 11a and 14a), the values of $3.88 \times 10^{-12}$ and $9.08 \times 10^{-12} \mathrm{~m}^{2}$, respectively, have been obtained for the parameter $D \cdot t$. Setting the four values of time $(t)$ used before, the corresponding values of diffusivity $(D)$ have been fixed, and using Equation (2) the corresponding equivalent temperatures $\left(T_{\text {eq. }}\right)$ have been calculated.

For the ASTM A283/Alloy 59 interface the same value of $D_{\mathrm{o}}$ and $Q$ for Ni diffusion in $\gamma$-Fe introduced in the previous analysis of the ASTM A515 Gr.60/AISI 304 L interface, have been used. Table 5 illustrates the resulting couples of $T_{\text {eq. }}$ and $t$. 
Table 5. Parameter $D \cdot t$ fitting value, analysed couples of $t$ and $T_{\text {eq., }}$ and corresponding values of $D$, for Ni diffusion at the interface ASTM A283/Alloy 59.

\begin{tabular}{cccc}
\hline $\boldsymbol{D} \cdot \boldsymbol{t}\left(\mathbf{m}^{\mathbf{2}}\right) \mathbf{( E x p} /$ Fitted) & $\boldsymbol{t}(\mathbf{s})($ Set Values) & $\boldsymbol{D}\left(\mathbf{m}^{\mathbf{2}} \mathbf{s}\right)$ (Calculated) & $\boldsymbol{T}$ (K) (Calculated) \\
\hline $3.88 \times 10^{-12}$ & 3600 & $1.08 \times 10^{-15}$ & 1434 \\
$3.88 \times 10^{-12}$ & 3000 & $1.29 \times 10^{-15}$ & 1443 \\
$3.88 \times 10^{-12}$ & 2400 & $1.62 \times 10^{-15}$ & 1455 \\
$3.88 \times 10^{-12}$ & 1800 & $2.16 \times 10^{-15}$ & 1472 \\
\hline
\end{tabular}

Interface ASTM A283/Alloy 59 presents substantial similarity with the diffusion conditions of $\mathrm{Ni}$ across the interface ASTM A515 Gr.60/AISI $304 \mathrm{~L}$, with the exception of the different content of Ni in the cladding alloy. Therefore, the analyses of diffusion profiles simulated for different values of temperature fluctuations around the equivalent values provide results that are quite similar to those represented in Figure 17 for the first interface, showing that: low duration of the diffusion transient increases the robustness of the diffusion process to temperature fluctuations; conversely, a high duration of the transient extends the diffusion depth, which is a beneficial condition for mechanical strengthening of the interface.

For the AISI 1010/Monel 400 interface, lower cladding temperatures have to be set, because of the melting temperature of Monel 400 (a value of solidus temperature just below $1600 \mathrm{~K}$ corresponds to the Ni-Cu alloy composition reported in Table 3 [33]). Hence, in this case, the diffusion of $\mathrm{Ni}$ in the $\alpha$-Fe field has been considered, and the values $D_{\mathrm{o}}=1.30 \times 10^{-4} \mathrm{~m}^{2} / \mathrm{s}$ and $Q=234.5 \mathrm{~kJ} / \mathrm{mol}$ [34] have been used in Equation (2). Table 6 provides the resulting couples of $T_{\text {eq. }}$ and $t$ for $\mathrm{Ni}$ diffusion.

Table 6. Parameter $D \cdot t$ fitting value, analysed couples of $t$ and $T_{\text {eq., }}$ and corresponding values of $D$, for Ni diffusion at the interface AISI 1010/Monel 400.

\begin{tabular}{cccc}
\hline $\boldsymbol{D} \cdot \boldsymbol{t}\left(\mathbf{m}^{\mathbf{2}}\right) \mathbf{( E x p} /$ Fitted) & $\boldsymbol{t}(\mathbf{s})$ (Set Values) & $\boldsymbol{D}\left(\mathbf{m}^{\mathbf{2}} \mathbf{s}\right)($ Calculated) & $\boldsymbol{T}(\mathbf{K})$ (Calculated) \\
\hline $9.08 \times 10^{-12}$ & 3600 & $2.52 \times 10^{-15}$ & 1144 \\
$9.08 \times 10^{-12}$ & 3000 & $3.03 \times 10^{-15}$ & 1152 \\
$9.08 \times 10^{-12}$ & 2400 & $3.78 \times 10^{-15}$ & 1163 \\
$9.08 \times 10^{-12}$ & 1800 & $5.04 \times 10^{-15}$ & 1177 \\
\hline
\end{tabular}

Figure 19 shows the diffusion profiles that were simulated for different values of temperature fluctuations around the equivalent value $(1144 \mathrm{~K})$ for $t=3600 \mathrm{~s}$. This simulation differs from the previous ones, in that it presents a change in the properties of the diffusion region, which arises due to positive high temperature fluctuations: for increases in $T_{\text {eq. }}$ that are greater than $+30 \mathrm{~K}$, the diffusion of $\mathrm{Ni}$ leaves the $\alpha$-Fe field to enter the $\gamma$-Fe field, being $1183 \mathrm{~K}$ the transition temperature between these two fields commonly assumed for diffusion in iron matrix [35]; the result is the downfall of the diffusion mechanism for fluctuations of $+50 \mathrm{~K}$ and $+100 \mathrm{~K}$, being well represented by the dashed curves in the figure, which would be a particularly insidious phenomenon if arisen during the cladding process.

Contrary to the first interface, in the last two cases analysed, the diffusion of carbon does not represent a critical issue, due to the negligible content that characterizes this element in the base material for the interface ASTM A283/Alloy 59 (Table 2), and the absence of chromium in the cladding material for the interface AISI 1010/Monel 400 (Table 3). 


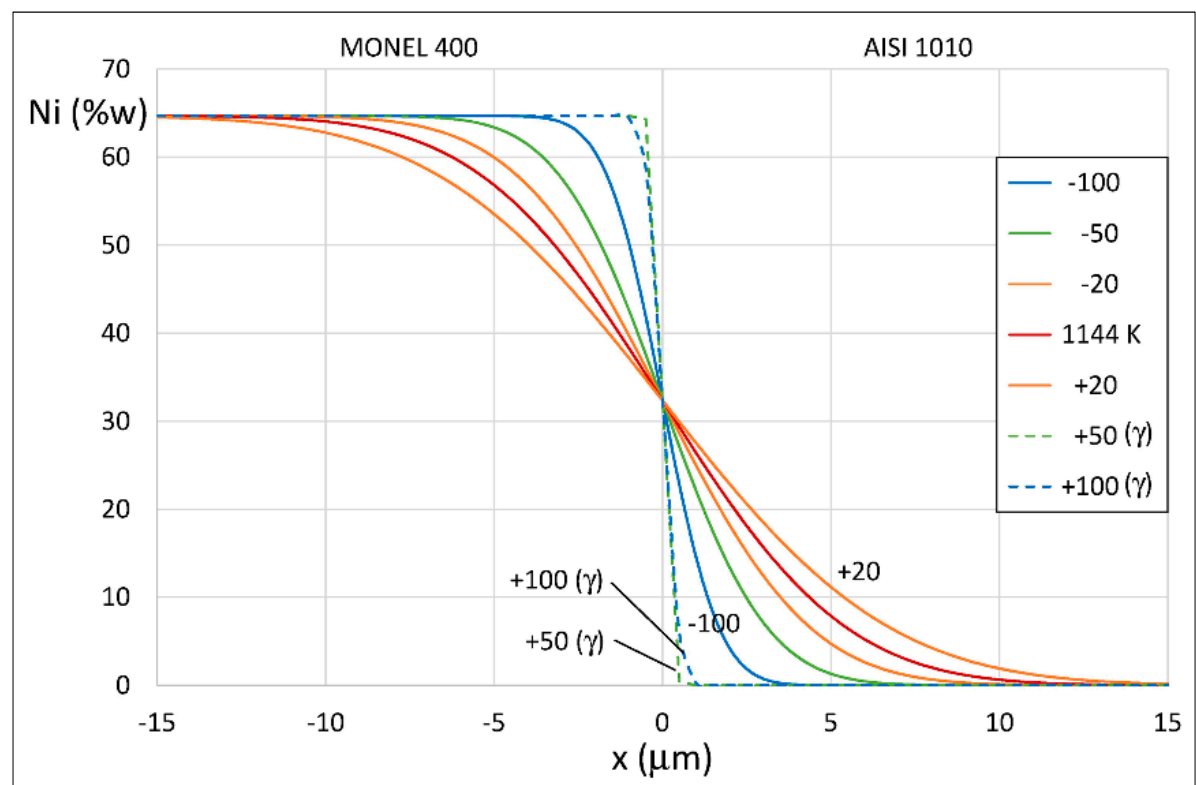

Figure 19. Concentration profiles of nickel along a line orthogonal to the interface AISI 1010/Monel 400 $\mathrm{Cu}-\mathrm{Ni}$ alloy, calculated for different fluctuations of $T_{\text {eq. }}(t=3600 \mathrm{~s})$.

\section{Conclusions}

The proposed approach based on the experimental investigations of the microstructural properties, coupled with the theoretical analysis of diffusion phenomena and their effects on bonding, allowed for obtaining a comprehensive metallurgical characterization of the interfaces in carbon steel plates clad by hot rolling with austenitic stainless steel and high Ni content alloys.

Metallographic investigations have shown the formation of continuous cladding interfaces, with microstructural modifications due to diffusion phenomena. The interdiffusion of the substitution elements caused a shift of the cladding interface towards the base steel, contributing to the formation of good bonds with cladding material. In addition, in the ASTM A515Gr.60 steel clad with AISI 304 L, we observed carbide precipitation and, consequently, the sensitization of the austenitic steel to the intergranular corrosion. However, in all of the examined cases, the wideness of the zones affected by microstructural changes was at least of an order of magnitude lower than the thickness of the cladding layer.

The simulations based on theoretical modelling have shown how much the process temperature is decisive for the wideness of the layers interested by diffusion: in general, reductions in temperature of few tens of centigrade generate evident reductions in the diffused layers, which can be detrimental for bonding strength. Concerning carbon diffusion in the first interface, the diffusion depth increases markedly at the increasing of the process temperature, but luckily its low concentration only makes sensitization possible for an extremely long permanence time at high temperature during the cooling stage after hot rolling. With regard to the effect of the diffusion time, process settings that provide longer transient durations, as expected, result in being more effective for bonding strength, due to the consequent widening of the diffusion depth; on the other hand, they conflict with the beneficial effect that shorter diffusion transients have in terms of the robustness of the diffusion processes to temperature fluctuations.

These results, as a whole, validate the choice to found the theoretical simulations on the concentration profiles shape factor $D \cdot t$, which acts as an efficiency parameter of diffusion bonding, to be well-balanced in setting process parameters. By means of this approach, which allows for operating on the relationship between diffusion time and temperature, the analytical investigation highlights how the shorter is the duration of the diffusion transient and the higher the temperature, the lower is the sensitivity of the diffusion processes to temperature fluctuations, with evident effects on the features 
uniformity in hot rolled clad plates. Finally, particular attention should be paid when the process conditions are close to a limit of phase field stability: in this case, as highlighted by the characterization of the third interface (AISI 1010/Monel 400), temperature fluctuations can determine phase changes that have a strong impact on the diffusion depth.

Author Contributions: Conceptualization, F.G., S.M., F.M., A.S.; methodology, F.G., S.M., F.M., A.S.; investigation, F.G., S.M., F.M., A.S..; resources, F.G., A.S.; data curation, F.G., S.M., F.M., A.S.; writing-original draft preparation, F.G., S.M., F.M., A.S.; visualization, F.G., S.M., F.M., A.S.; supervision, F.G., A.S.; funding acquisition, F.G., A.S. All authors have read and agreed to the published version of the manuscript.

Funding: This research was partly funded by the University of Catania within the project "Piano della Ricerca Dipartimentale 2016-2018" of the Department of Civil Engineering and Architecture.

Conflicts of Interest: The authors declare no conflict of interest.

\section{References}

1. Smith, L. Engineering with Clad Steel; Nickel Development Institute: Beijing, China, 2012.

2. Ban, H.Y.; Bai, R.S.; Chung, K.F.; Zhu, J.C.; Bai, Y. Research progress on material properties of clad steel. In Proceedings of the 12th International Conference on Advances in Steel-Concrete Composite Structures ASCCS 2018, València, Spain, 27-29 June 2018.

3. Song, H.; Shin, H.; Shin, Y. Heat-treatment of clad steel plate for application of hull structure. Ocean Eng. 2016, 122, 278-287. [CrossRef]

4. Roll-Bonded Clad Plates; Voest Alpine Grobblech GmbH: Linz, Austria, 2016.

5. Dhib, Z.; Guermazi, N.; Gaspérini, M.; Haddar, N. Cladding of low-carbon steel to austenitic stainless steel by hot-roll bonding: Microstructure and mechanical properties before and after welding. Mat. Sci. Eng. A-Struct. 2016, 656, 130-141. [CrossRef]

6. Liu, B.X.; An, Q.; Yin, F.X.; Wang, S.; Chen, C.X. Interface formation and bonding mechanisms of hot rolled stainless steel clad plate. J. Mat. Sci. 2019, 54, 11357-11377. [CrossRef]

7. Qian, M.; Lim, L.C.; Chen, Z.D.; Chen, W.L. Parametric studies of laser cladding processes. J. Mat. Process. Tech. 1997, 63, 590-593. [CrossRef]

8. Anjos, M.A.; Vilar, R.; Qiu, Y.Y. Laser cladding of ASTM S31254 stainless-steel on a plain carbon steel substrate. Surf. Coat. Tech. 1997, 92, 142-149. [CrossRef]

9. Costanza, G.; Crupi, V.; Guglielmino, E.; Sili, A.; Tata, M.E. Metallurgical characterization of an explosion welded aluminum/steel joint. Metall. Ital. 2016, 11, 17-22.

10. Lee, K.S.; Kim, J.S.; Joa, Y.M.; Lee, S.E.; Heo, J.; Chang, Y.W.; Lee, Y.S. Interface-correlated deformation behavior of a stainless steel-Al-Mg 3-ply composite. Mater. Charact. 2013, 75, 138-149. [CrossRef]

11. Mudhaffar, M.A.; Saleh, N.A.; Aassy, A. Influence of hot clad rolling process parameters on life cycle of reinforced bar of stainless steel carbon steel bars. Procedia Manufact. 2017, 8, 353-360. [CrossRef]

12. Shen, W.; Feng, L.; Feng, H.; Cao, Y.; Liu, L.; Cao, M.; Ge, Y. Preparation and characterization of 304 stainless steel/Q235 carbon steel composite material. Results Phys. 2017, 7, 529-534. [CrossRef]

13. Li, H.; Zhang, L.; Zhang, B.; Zhan, Q. Microstructure characterization and mechanical properties of stainless steel clad plate. Materials 2019, 12, 509. [CrossRef]

14. Dhib, Z.; Guermazi, N.; Ktari, A.; Gasperini, M.; Haddar, N. Mechanical bonding properties and interfacial morphologies of austenitic stainless steel clad plates. Mat. Sci. Eng. A-Struct. 2017, 696, 374-386. [CrossRef]

15. Wang, S.; Liu, B.X.; Chen, C.X.; Feng, J.H.; Yin, F.X. Microstructure, mechanical properties and interface bonding mechanism of hot-rolled stainless steel clad plates at different rolling reduction ratios. J. Alloys Compd. 2018, 766, 517-526. [CrossRef]

16. Yu, T.; Jing, Y.A.; Yan, X.; Li, W.; Pang, Q.; Jing, G. Microstructures and properties of roll-bonded stainless/medium carbon steel clad plates. J. Mater. Process. Technol. 2019, 266, 264-273.

17. Missori, S.; Murdolo, F.; Sili, A. Studio delle interfacce in acciai ferritici placcati a caldo con acciaio austenitico o lega a base di Ni. Metal. Ital. 2003, 3, 21-26.

18. Missori, S.; Murdolo, F.; Sili, A. Single-pass laser beam welding of clad steel plate. Weld. J. 2004, 83, 65s-71s.

19. Liu, B.X.; Yin, F.X.; Dai, X.L.; He, J.N.; Fang, W.; Chen, C.X.; Dong, Y.C. The tensile behaviors and fracture characteristics of stainless steel clad plates with different interfacial status. Mat. Sci. Eng. A-Struct. 2017, 679, 172-182. [CrossRef] 
20. Zhang, X.J.; Li, L.; Liu, H.Y.; Yin, F.X. Application of insert layer in manufacturing clad metal plates. Steel Roll. 2013, 30, 45-49.

21. Feng, Y.; Yu, H.; Luo, Z.; Xie, G.; Misra, R.D.K. The impact of surface treatment and degree of vacuum on the interface and mechanical properties of stainless steel clad plate. Materials 2018, 11, 1489. [CrossRef]

22. Wu, Z.J.; Peng, W.F.; Shu, X.D. Influence of rolling temperature on interface properties of the cross wedge rolling of 42CrMo/Q235 laminated shaft. Int. J. Adv Manuf. Technol. 2017, 9, 517-526. [CrossRef]

23. Jin, H.; Zhang, L.; Yi, Y. Effect of rolling reduction rate on the microstructure of hot rolling stainless steel clad plate. IOP Conf. Ser. Mater. Sci. 2018, 394, 1-5. [CrossRef]

24. Shewmon, P. Diffusion in Solids; The Minerals, Metals \& Materials Society: Pittsburgh, PA, USA, 1989.

25. Wang, B.; Zhang, F.; Chen, S.L.; Kou, S. Computational simulation of diffusion process in multicomponent and multiphase systems in diffusion bonding. Sci. Technol. Weld. Joi. 2013, 18, 451-457. [CrossRef]

26. Chen, C.X.; Liu, M.Y.; Liu, B.X.; Yin, F.X.; Dong, Y.C.; Zhang, X.; Zhang, F.Y.; Zhang, Y.G. Tensile shear sample design and interfacial shear strength of stainless steel clad plate. Fusion. Eng. Des. 2017, 125, 431-441. [CrossRef]

27. Kotecki, D.J. A martensite boundary on the WRC-1992 diagram: The effect of manganese. Welding J. 2000, 79, 346-354.

28. Missori, S.; Sili, A. Prediction of weld metal microstructure in laser beam weld metal clad steel. Metallurgist 2018, 62, 84-92. [CrossRef]

29. Gomez, X.; Echeberria, J. Microstructure and mechanical properties of low alloy steel T11-austenitic steel 347H bimetallic tubes. Mater. Sci. Technol. 2000, 16, 187-193. [CrossRef]

30. Badia, M.; Vignes, A. Diffusion du fer, du nickel et du cobalt dans les metaux de transition du groupe du fer. Acta Metall. 1969, 17, 177-187. [CrossRef]

31. Agren, J. A revised expression for the diffusivity of carbon in binary Fe-C austenite. Scripta Metall. 1986, 20, 1507-1510. [CrossRef]

32. Weman, K. Welding Processes Handbook; Woodhead Publishing Ltd.: Cambridge, UK, 2003.

33. Okamoto, H.; Schlesinger, M.E.; Mueller, E.M. ASM Handbook Vol. 3: Alloy Phase Diagrams; ASM International: Materials Park, OH, USA, 2016.

34. Hirano, K.; Cohen, M.; Averbach, B.L. Diffusion of nickel into iron. Acta Metall. 1961, 9, 440-445. [CrossRef]

35. Mehrer, H. Diffusion in Solid Metals and Alloys; Springer: Berlin, Germany, 1990. 